\title{
Treatment of a complex tracheobronchial malignant stenosis with a modified conical semicovered self-expanding stent
}

\author{
Claudio Andreetti, $\mathrm{PhD}, \mathrm{MD},{ }^{\mathrm{a}}$ Antonio D'Andrilli, $\mathrm{PhD}, \mathrm{MD},{ }^{\mathrm{a}}$ Mohsen Ibrahim, $\mathrm{PhD}, \mathrm{MD},{ }^{\mathrm{a}}$ and \\ Erino Angelo Rendina, $\mathrm{PhD}, \mathrm{MD},{ }^{\mathrm{a}, \mathrm{b}}$ Rome, Italy
}

The management of complex malignant stenosis that involves the trachea and one or both main bronchi in nonoperable patients represents a challenging issue. The aim of the endoscopic treatment is to re-establish the lumen and to position a stent to ensure stable airway patency. Currently, the silicon Y-stent after laser resection is the most commonly used option. ${ }^{1}$ We describe a case of tracheobronchial malignant stricture that was successfully treated with a modified conical semi-covered self-expanding nitinol stent.

\section{CLINICAL SUMMARY}

A 62-year-old man with nonoperable squamous cell lung cancer (clinical stage IV, T4 N2 M1) was seen with a history of progressive cough, hemoptysis, and shortness of breath. A computed tomographic scan showed a mass in the right hilar region with a severe stricture of the distal trachea at the right tracheobronchial corner and of the right main bronchus (RMB). A bronchoscopic evaluation confirmed a mass that obstructed the lower trachea to such an extent that it

From the Department of Thoracic Surgery, ${ }^{a}$ University of Rome, La Sapienza, Sant'Andrea Hospital, and Fondazione Eleonora Lorillard Spencer Cenci, ${ }^{b}$ Rome, Italy.

Disclosures: Authors have nothing to disclose with regard to commercial support. Received for publication Nov 26, 2012; revisions received Feb 1, 2013; accepted for publication March 5, 2013; available ahead of print April 5, 2013.

Address for reprints: Claudio Andreetti, PhD, MD, Department of Thoracic Surgery,

Sant'Andrea Hospital, Via di Grottarossa 1035, 00189 Rome, Italy (E-mail: andreetticlaudio@gmail.com).

J Thorac Cardiovasc Surg 2013;146:488-9

$0022-5223 / \$ 36.00$

Copyright (c) 2013 by The American Association for Thoracic Surgery

http://dx.doi.org/10.1016/j.jtcvs.2013.03.007 was not possible to explore the RMB (Figure 1, A-D). The patient underwent endoscopic tumor ablation and stent application. The procedure was performed using a Dumon rigid bronchoscope (Efer Medical, La Ciotat Cedex, France) under local anesthesia and intravenous deep sedation. The endotracheal-endobronchial mass was removed via a mechanical coring technique using a neodymiumdoped yttrium aluminium perovskite (Nd-YAP) laser (Lokki Lis Laser-Bryan Corporation, Woburn, Mass). At the end of the procedure, the tracheal and the RMB lumen were re-established. The right upper bronchus was free from tumor. Because of the caliber discrepancy between the trachea and the RMB, a conical stent was considered the ideal prosthetic option to maintain the airway patency. Therefore, we used a custom-made, conical, semicovered, self-expanding nitinol stent (Tracheobronxane Silmet, Novatech SA, France) with a proximal diameter (tracheal) of $22 \mathrm{~mm}$, a distal diameter (bronchial) of 16 $\mathrm{mm}$, a length of $60 \mathrm{~mm}$, and a distal portion of $2 \mathrm{~cm}$ with no cover, to prevent the obstruction of the right upper lobe (RUL) bronchus, which is close to the tracheobronchial angle.

The proximal end of the stent was positioned in the lower trachea and the uncovered distal end was positioned in the right intermediate bronchus, allowing effective ventilation of the RUL. To allow ventilation of the left main bronchus, which was occluded by the prosthesis wall just above the carina, the polyester cover of the stent was partially ablated using the Nd-YAP laser with a low frequency $(700 \mathrm{~mJ}, 10$ $\mathrm{Hz}, 7 \mathrm{~W}$ ), leaving the nitinol support intact (Figure 2, $A-D)$. We have previously tested the safety of this procedure on a laboratory model. An immediate improvement in the

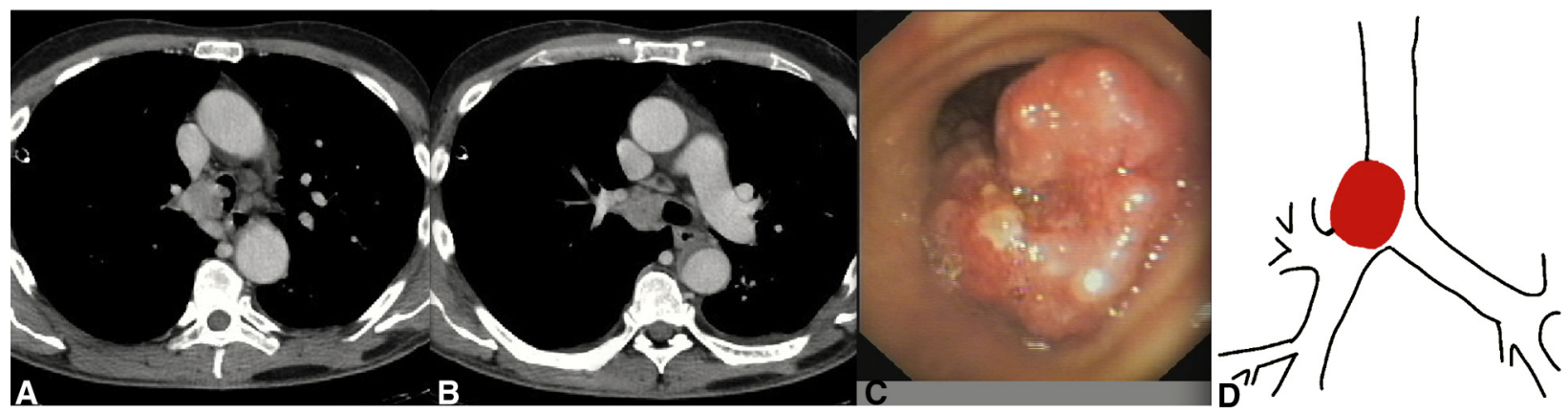

FIGURE 1. Right lung hilar tumor involving the lower trachea and the right main bronchus with severe airway obstruction. Computed tomography showing obstruction at the levels of the distal trachea (A) and the right main bronchus (B). C, Endoscopic view (distal trachea). D, Schematic picture. 


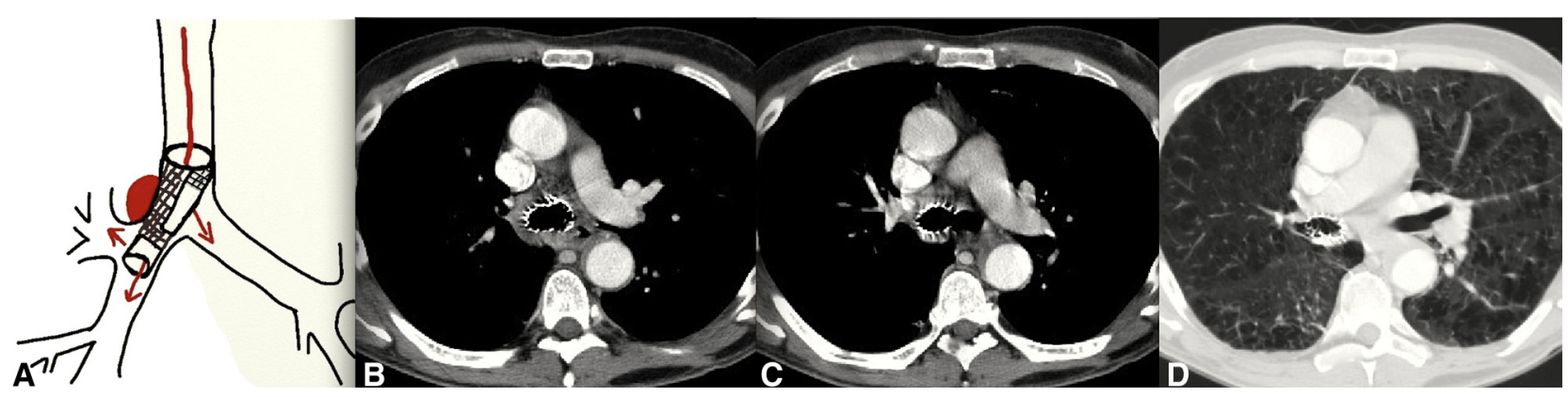

FIGURE 2. Final result of the endoscopic treatment. A, Schematic picture showing the conical stent in site. Uncovered portions of the stent wall are reproduced in white. An area of cover of approximately $1 \mathrm{~cm}^{2}$ was removed to allow ventilation of the left main bronchus. B, Computed tomographic (CT) image showing the endotracheal prosthesis at the level of the carina. C, CT image showing the stent fenestration at the level of the origin of the left main bronchus. D, CT showing the uncovered distal end of the stent in the intermediate bronchus that allows for effective ventilation of the right upper lobe. Tracheobronchial evaluation performed at 1 and 4 months bronchoscopically and at 5, 7, and 9 months by CT scan showed no dislocation, no stent damage or occlusion, and no significant granulation.

patient's general condition was observed. The patient died 10 months after the stent placement as the result of systemic oncological progression.

\section{DISCUSSION}

Endoscopic treatment of malignant tracheobronchial stenosis represents a minimally invasive, but complex, option for improving the cardiorespiratory status in nonoperable patients. If the obstruction involves the trachea and one or both main bronchi, the choice of a stent enabling a stable airway patency with effective ventilation of the main and upper lobe bronchi is controversial. Currently, the silicone Y-stent with a modified right arm for RUL ventilation is most commonly used. ${ }^{2,3}$ However, the Y-stent covers the trachea and both main bronchi (even if only one is obstructed) and has a deep impact on the mucosa and mucus clearance. ${ }^{4}$ For this reason, it is generally not well tolerated by patients and the risk of obstruction by mucus and/or granuloma formation is high. Furthermore, such silicone stents are often difficult to deploy and, because of the wall thickness, provide reduced area for ventilation through the trachea and main stem bronchi. Self-expanding semicovered nitinol stents overcome such difficulties because they are easy to deploy, extremely thin, and, thus, offer a low profile with minimal luminal reduction. The disadvantage in using these stents for malignancies located close to bronchial bifurcations results mostly from obstruction of main stem or lobar bronchi by the covered portion of the stent. The modified procedure for using the conical, semi-covered, self-expanding nitinol stent described herein allowed for treatment of a complex right tracheobronchial stenosis and provided optimal ventilation of the RUL and the main left bronchus and mucus clearance. To our knowledge, the use of the Nd-YAP laser to selectively remove the polyester support to ventilate the left main stem bronchus has never been reported. We believe that reporting the safe use of this technique can lead to a significant increase in the utility of covered self-expanding metal stents for the treatment of complex airway obstructions. Furthermore, because of the conical shape of the prosthesis and the small caliber of its distal end, decubitus of the uncovered stent portion on the tracheobronchial mucosa was avoided, thus decreasing the risk of granuloma. ${ }^{5}$

We thank Dr Elisabette Grigioni for editorial revision.

\section{References}

1. Oki M, Saka H, Kitagawa C, Kogure Y, Mori K, Kajikawa S, et al. Double Y-stent placement for tracheobronchial stenosis. Respiration. 2010;279:245-9.

2. Peled N, Shitrit D, Bendayan D, Kramer MR. Right upper lobe "window" in right main bronchus stenting. Eur J Cardiothorac Surg. 2006;30:388-90.

3. Dumon JF, Dumon MC. Dumon-Novatech Y-stents: a four-year experience with 50 tracheobronchial tumors involving the carina. J Bronchol. 2000;7:26-32.

4. Oki M, Saka H, Kitagawa C, Kogure Y. Silicone Y-stent placement on the carina between bronchus to the right upper lobe and bronchus intermedius. Ann Thorac Surg. 2009;87:971-4.

5. Andreetti C, D'Andrilli A, Ibrahim M, Ciccone AM, Maurizi G, Mattia A, et al. Effective treatment of post-pneumonectomy bronchopleural fistula by conical fully covered self-expandable stent. Interact Cardiovasc Thorac Surg. 2012;14: 420-3. 